patients $(75 \%)$, presented by polyarthritis in $7 / 9(77.8 \%)$, and oligoarthritis in 2/9 $(22.2 \%)$. Two patients $(16.7 \%)$ had cataract, one $(8.3 \%)$ had bilateral uveitis, and one $(8.3 \%)$ had optic atrophy. Sensorineural hearing loss was observed only in $3 / 12(25 \%)$. Hydrocephalus was detected in 3/12 (25\%). Delayed mental and psycho-speech development was observed in 6/12 (50\%) patients. In 3/12 (25\%), the development of MAS was recorded.

All patients had nucleotide variants in NLRP3 gene. According to NGS results and clinical characteristics, $8 / 12(66.7 \%)$ patients were diagnosed with MWS and $4 / 12(33.3 \%)$ had CINCA/NOMID syndrome. In children with MWS, heterozygous variant c. $2113 C>A$ in $N L R P 3$ gene was the most common (5/8 $(62.5 \%)$ patients). One of $8(12.5 \%)$ patients with novel heterozygous variant c. $2861 C>T$ was detected; also one child (12.5\%) have heterozygous variant c.598G>A and one $(12.5 \%)$ - heterozygous variant $c .943 A>G$. Four patients with CINCA/ NOMID syndrome also had heterozygous variants in NLRP3 gene: c.598G $>A$, c. $2173 C>A, C .1991 T>C$ and $C .796 C>T$.

Prior to genetic testing, $12 / 12$ (100\%) patients received NSAIDs; $6 / 12$ (50\%) were treated with oral glucocorticoids (GC), 3/12 (25\%) - with intravenous GC, 2/12 $(22.2 \%)$ - with methotrexate. Biologics treatment included: $5 / 12(41.7 \%)$ CAN, $4 / 12(33.3 \%)$ tocilizumab, and $1 / 12(8.3 \%)$ etanercept. After genetic testing, $7 / 12$ $(58.3 \%)$ patients were successfully switched to CAN. Only $1 / 12(8.3 \%)$ child with MWS developed secondary inefficiency on CAN treatment.

Conclusion: Systemic manifestations were detected in $91.6 \%$ of children, while active arthritis was observed in $75 \%$ of patients, which can cause difficulties in the diagnosis and treatment of CAPS. The effectiveness of canakinumab therapy was estimated in $91.6 \%$ of patients. The most frequent variant of the NLRP3 gene in MWS was c.2113C>A. In patients with CINCA/NOMID syndrome all nucleotide variants were individual.

Disclosure of Interests: Meyri Shingarova: None declared, Ekaterina Alexeeva Grant/research support from: Roche, Pfizer, Centocor, Novartis, Speakers bureau: Roche, Novartis, Pfizer., Tatyana Dvoryakovskaya: None declared, Kirill Savostyanov: None declared, Aleksander Pushkov: None declared, Evgeniya Chistyakova: None declared, Ksenia Isaeva: None declared, Aleksandra Chomakhidze: None declared, Olga Lomakina: None declared, Rina Denisova: None declared, Anna Mamutova: None declared, Anna Fetisova: None declared, Marina Gautier: None declared, Dariya Vankova: None declared, Elizaveta Krekhova: None declared, Ivan Kriulin: None declared, Natalia Zhurkova: None declared, Rustam Tepaev: None declared, Alina Alshevskaya: None declared, Andrey Moskalev: None declared

DOI: 10.1136/annrheumdis-2020-eular.5814

\section{FRI0465 TOFACITINIB POPULATION PHARMACOKINETICS IN CHILDREN WITH JUVENILE IDIOPATHIC ARTHRITIS: A POOLED ANALYSIS OF DATA FROM THREE CLINICAL STUDIES}

C. Vong ${ }^{1}$, X. Wang ${ }^{2}$, A. Hazra ${ }^{2}$, A. Mukherjee ${ }^{2}$, T. Nicholas ${ }^{2}$, C. Chang ${ }^{2}$. ${ }^{1}$ Pfizer Inc, Cambridge, MA, United States of America; ${ }^{2}$ Pfizer Inc, Groton, CT, United States of America

Background: Tofacitinib is an oral JAK inhibitor that is being investigated for juvenile idiopathic arthritis (JIA).

Objectives: To describe tofacitinib pharmacokinetics $(P K)$ in patients with JIA, identify potential covariates accounting for variability in exposure, assess the formulation effect of oral solution vs tablet and propose a simplified dosing regimen.

Methods: This was a pooled analysis of data from 3 tofacitinib clinical studies in patients with JIA aged $2-<18$ years: a Phase 1, open-label (OL), non-randomised study (NCT01513902); a Phase 3, randomised, double-blind, placebo-controlled, withdrawal study (NCT02592434); and an OL long-term extension study (NCT01500551). Tofacitinib was dosed at $5 \mathrm{mg}$ twice daily (BID) in patients $\geq 40 \mathrm{~kg}$ or at body weight (BW)-based lower doses BID in patients $<40 \mathrm{~kg}$, to achieve average concentrations $\left(\mathrm{C}_{\text {avg }}\right)$ comparable with those in patients receiving $5 \mathrm{mg}$ BID. A sparse PK sampling scheme was applied, and the plasma samples were assayed using a validated, sensitive and specific high-performance liquid chromatography tandem mass spectrometric method (lower limit of quantification $=0.100 \mathrm{ng} / \mathrm{mL}$ ). A nonlinear mixed-effects modelling approach was used for the population PK model, and population parameter variability was assumed to be log-normally distributed. Covariates relating to patient demographics, disease characteristics, concomitant medications and formulation (oral solution vs tablet) were selected using a stepwise covariate modelling approach, and parameter-covariate relationships were evaluated using stepwise forward-inclusion $(p<0.05)$ backward-deletion $(p<0.001)$ procedures. The effect of time-varying BW on oral clearance (CL/F) and apparent volume of distribution (V/F) was characterised using an allometric model. Final model quality was assessed by Visual Predictive Checks (VPCs)

Results: Of 246 patients in the analysis, $74.0 \%$ were female; $87.8 \%$ were white, $2 \%$ were black, $10.2 \%$ were 'other' races and no patients were Asian. Median (range)
BW was 46.3 (11.1-121.8) kg. Initially, 100 patients received oral solution and 146 patients received tablets; 11 patients switched formulations during the studies. A one compartment disposition model with first-order absorption and a lag time sufficiently described the data. Final estimates for $\mathrm{CL} / \mathrm{F}, \mathrm{V} / \mathrm{F}$ and the first-order absorption rate constant $\left(k_{\mathrm{a}}\right)$ for tablets were $26.1 \mathrm{~L} / \mathrm{hr}, 89.2 \mathrm{~L}$ and $2.78 \mathrm{hr}^{-1}$, respectively. The only statistically significant covariate was a formulation effect on $\mathrm{k}$. All parameters were estimated adequately. Estimated allometric exponents were 0.310 for $\mathrm{CL} / \mathrm{F}$ and 0.537 for V/F. Absorption was described with an estimated lag time of $0.186 \mathrm{hr}$, and the oral solution had a 1.64 -fold faster absorption rate vs the tablet. VPCs sufficiently described the observed data over time, across BWs and ages. Given the PK characterisation and variability in patients with JIA, a simplified dosing scheme was proposed, targeting $\mathrm{C}_{\text {avg }}$ values equivalent to those in patients receiving $5 \mathrm{mg}$ BID: $3.2 \mathrm{mg}$ BID solution in patients $10-<20 \mathrm{~kg} ; 4 \mathrm{mg}$ BID solution in patients $20-<40 \mathrm{~kg}$; and $5 \mathrm{mg}$ BID tablet or solution in patients $\geq 40 \mathrm{~kg}$

Conclusion: Tofacitinib population PK in patients with JIA were adequately described by a one compartment model parameterised in terms of CL/F, V/F and first-order absorption with a lag time. Drug absorption from the oral solution was faster than from the tablet. Tofacitinib does not require dose modification or restrictions for any covariates, except BW, to account for differences in $\mathrm{C}_{\mathrm{avg}}$. Based on the results of this analysis, a simplified BW-based dosing regimen was proposed. Acknowledgments: Study sponsored by Pfizer Inc. Medical writing support was provided by Sarah Piggott of CMC Connect and funded by Pfizer Inc.

Disclosure of Interests: Camille Vong Shareholder of: Pfizer Inc, at time of analysis, Employee of: Pfizer Inc, at time of analysis, Xiaoxing Wang Shareholder of: Pfizer Inc, Employee of: Pfizer Inc, Anasuya Hazra Shareholder of: Pfizer Inc, at time of analysis, Employee of: Pfizer Inc, at time of analysis, Arnab Mukherjee Shareholder of: Pfizer Inc, Employee of: Pfizer Inc, Timothy Nicholas Shareholder of: Pfizer Inc, Employee of: Pfizer Inc, Cheng Chang Shareholder of: Pfizer Inc, Employee of: Pfizer Inc

DOI: 10.1136/annrheumdis-2020-eular.400

\section{FRI0466}

NO DISEASE PROGRESSION AFTER 36 MONTHS FOLLOW UP IN THE JUVENILE SYSTEMIC SCLERODERMA INCEPTION COHORT

I. Foeldvari ${ }^{1}$, J. Klotsche ${ }^{2}$, O. Kasapcopur ${ }^{3}$, A. Adrovic ${ }^{3}$, M. T. Terreri ${ }^{3}$, R. Cimaz ${ }^{3}$, M. Katsikas ${ }^{3}$, D. Nemcova ${ }^{3}$, M. J. Santos ${ }^{3}$, J. Brunner ${ }^{3}$, M. Kostik ${ }^{3}$ K. Minden ${ }^{2}$, A. Patwardhan ${ }^{3}$, K. Torok ${ }^{3}$, N. Helmus ${ }^{1} .{ }^{1}$ Hamburg Centre for Pediatric and Adolescence Rheumatology, Hamburg, Germany; ${ }^{2}$ German Rheumatism Research Center, Berlin, Germany; ${ }^{3}$ jSSc Collaborative Group, Hamburg, Germany

Background: Juvenile systemic scleroderma (jSSc) is an orphan disease with a prevalence of 3 in 1000000 children. There is rare longitudinal prospective follow up data of patients with jSSc. In the international juvenile systemic scleroderma cohort (JSScC) patients are followed with a standardized assessment prospectively.

Objectives: To assess the changes regarding organ involvement pattern and patients related outcomes after 36 months follow up in the JSScC.

Methods: Patients diagnosed according the ACR 2013 criteria for systemic sclerosis were included, if they developed the first non-Raynaud symptom before the age of 16 and were under the age of 18 at the time of inclusion. Patients were followed prospectively every 6 months with a standardized assessment.

Results: 39 patients in the JSScC had 36 months follow up. $80 \%$ had a diffuse subtype. $95 \%$ of the patients were Caucasian origin. 31 of the patients were female $(80 \%)$. Mean disease duration at time of inclusion was 3.5 years. Mean age onset of Raynaud's was 8.8 years and mean age of onset at the first non-Raynaud's was 9.5 years. Around $30 \%$ of the patients were anti-Scl70 positive and none of them anti-centromere positive. The MRSS dropped from the time point of the inclusion into the cohort from 13.9 to 11.8 after 36 months. Pattern of organ involvement did not show any significant change, beside the increase of the nailfold capillary changes from $49 \%$ to $73 \%(p=0.037)$. No renal crisis occurred. No mortality was observed.

They were positive significant changes in the patient related outcomes. The phy sician global disease activity decreased from 40.0 to 22.1 assessed on a VAS scale of 0 to $100(p<0.001)$

Patients global disease activity decreased from 43.3 to 20.4 and patients global disease damage from 45.0 to 21.7 both assessed on a VAS scale of 0 to 100 $(\mathrm{p}<0.001)$.

Conclusion: After 36 months follow up, we could observe a significant improvement of patient related outcomes and only one significant change in organ pattern involvement. In a mostly diffuse subset patient population this is a very promising result regarding outcome.

Supported by the "Joachim Herz Stiftung"

Disclosure of Interests: Ivan Foeldvari Consultant of: Novartis, Jens Klotsche: None declared, Ozgur Kasapcopur: None declared, Amra Adrovic: None 
declared, Maria T. Terreri: None declared, Rolando Cimaz: None declared, Maria Katsikas: None declared, Dana Nemcova: None declared, Maria Jose Santos Speakers bureau: Novartis and Pfizer, Juergen Brunner Grant/research support from: Pfizer, Novartis, Consultant of: Pfizer, Novartis, Abbvie, Roche, BMS, Speakers bureau: Pfizer, Novartis, Abbvie, Roche, BMS, Mikhail Kostik: None declared, Kirsten Minden Consultant of: GlaxoSmithKline, Sanofi, Speakers bureau: Roche, Anjali Patwardhan: None declared, Kathryn Torok: None declared, Nicola Helmus: None declared

DOI: 10.1136/annrheumdis-2020-eular.2271

\section{FRI0467 DRUG SURVIVAL AND SAFETY OF BIOLOGICAL THERAPIES IN PATIENTS WITH JUVENILE IDIOPATHIC ARTHRITIS}

A. García Fernández ${ }^{1}$, A. Briones-Figueroa ${ }^{1}$, L. Calvo Sanz ${ }^{1}$, Á. AndreuSuárez ${ }^{1}$, J. Bachiller-Corral' ${ }^{1}$ A. Boteanu ${ }^{1} .{ }^{1}$ Hospital Ramón y Cajal, Rheumatology, Madrid, Spain

Background: Biological treatment (BT) has changed perspectives of JIA patients. Increasing data from real life experience have been reported.

Objectives: To compare drug survival, safety and efficacy of BT in patients with Juvenile Idiopathic Arthritis (JIA)

Methods: A retrospective observational study was conducted on JIA patients followed in a referal hospital and who had received at least one BT between 1999 and 2019.

Results: 218 BT in $130 \mathrm{JIA}$ patients were analyzed. $67.7 \%$ were women with a median age at diagnosis of 8 years old IQR (3-13) and a median age at the beginning of the BT of 15 years old IQR(7.8-21). $21.5 \%$ of the patients had uveitis during follow-up. BT were indicated due to: arthritis(73.9\%), uveitis(10.1\%), arthritis and uveitis(2.7\%), systemic activity(8.3\%) and macrophage activation syndrome (1,8\%). There were 130 BT started in 1st line, 55 in 2nd line, 20 in 3rd line, 10 in 4th line and 3 in 5 th line.

The 1st line BT most frequently indicated was Etarnecept(ETN) up to $40 \%$, followed by $30 \%$ Adalimumab(ADA) and $16,2 \%$ Infliximab(INF). The median duration of the 1 st line was 51 months IQR $(14-109,3)$. However, $53.8 \%$ of the 1st line BT were swiched: $28.3 \%$ due to adverse events, $25.7 \%$ due to 1 - failure and $25.7 \%$ due to $2 \circ$ failure. The BT that were discontinued were: INF (76.2\%) and Anakinra (ANAK) (75\%) due to adverse events and ETN $(59.6 \%)$ due to $1^{\circ}$ and $2^{\circ}$ failure. 55 patients started a 2 nd BT: $43.6 \%$ received ADA and $20 \%$ Tocilizumab (TCZ) with a median duration of 43 months IQR (12-90). 22 of 55 BT required a change: $75 \%$ of ETN and $59 \%$ of INF prescribed in 2 nd line were discotinued. The causes were: $40 \% 1^{\circ}$ failure, $28 \% 2^{\circ}$ failure and $12 \%$ remission. In 1 st line $87,6 \%$ of patients received TNF inhibitors, $74 \%$ mantained the target in 2nd line. In 3rd line TCZ was the most frequent BT. $71.5 \%$ of patients continue on BT. BT was withdrawn in 20 of 130 patients due to remission (40\%), adverse events $(30 \%)$, and pregnancy (10\%).

In the analysis by decades, 80 BT (36.7\%) were started from 1999 to 2008 and 138 BT (63.3\%) from 2009 to 2019. In the 1st decade ETN and INF were the most frequently prescribed and in the 2nd decade, ADA and TCZ $(p<0.0001)$. The 1 st BT in the 2 nd decade were indicated sooner compared to the 1st decade (1st decade: mean 119.5months $\operatorname{SD}(109.2)$; 2nd decade: mean 53.9 months SD(99.7); $p<0.0001)$. In 1st line BT, the BT prescribed in the 2 nd decade had a shorter duration than those in the 1st decade (1st decade: mean 84.1 months SD(71.8); 2nd decade: mean 51.7 months SD(5); $\mathrm{p}<0.0001)$.

In the survival analysis, TCZ and ADA were the BT with the highest survival $(p=0.001)$. Of the 31 patients that started TCZ, 61.3\% continue on TCZ, with a median duration of 46 month IQR(25-99) and $36 / 68(52,9 \%)$ still on ADA with a median duration of 61,5 month IQR(30.5-98).

Conclusion: $42.3 \%$ of patients required more than one BT. Since the onset of the BT there has been a change in prescription, probably related to the emerge of new targets and the evidence provided by clinical trials and guidelines. TCZ and ADA were the BT with the highest survival rate. On the other hand, INF and ANAK were the ones with the lowest survival rate. The most common causes of BT change in 1st line were adverse events in relation to INF and ANAK. In 2nd line there was a high rate of change in those patients who maintained TNFi, related to 1 - failure.

Disclosure of Interests: None declared

DOI: 10.1136/annrheumdis-2020-eular.4655

\begin{tabular}{|l|l}
\hline FRI0468 & SYSTEMIC AND CUTANEOUS POLYARTERITIS \\
& NODOSA IN COLOMBIAN PEDIATRIC PATIENTS: \\
& CUTANEOUS POLYARTERITIS IS NOT SO BENIGN
\end{tabular}

A. Medina ${ }^{1}$, M. Calle ${ }^{2}$, R. Eraso ${ }^{1,3,4}$, L. Hernandez ${ }^{1,4,5}$, J. S. Peinado Acevedo ${ }^{5}$, M. Velasquez ${ }^{6}$, A. Vanegas Va,5, $^{4, \text { D. Jaramillo Arroyave }}{ }^{4,5,7,8}$, C. Muñoz $z^{4,5,7,8}$.
${ }^{1}$ Universidad de Antioquia - Departamento de Pediatria, Medellin, Colombia; ${ }^{2}$ Universidad de Antioquia - Grupo de Estudio de Vasculitis Sistémicas, Medellin, Colombia; ${ }^{3}$ Hospital Pablo Tobón Uribe, Medellin, Colombia; ${ }^{4}$ Universidad de Anitoquia - Grupo de Reumatología, Facultad de Medicina - Departamento de Medicina Interna, Medellin, Colombia; ${ }^{5}$ Universidad de Antioquia - Grupo de Estudio de Vasculitis Sistémicas, Medellin, Colombia; ${ }^{6}$ Hospital Universitario San Vicente Fundacion, Hospital Infantil, Medellin, Colombia; ${ }^{7}$ Hospital Universitario San Vicente Fundacion, Medellin, Colombia; ${ }^{8}$ IPS Universitaria - Servicios de Salud - Universidad de Antioquia, Medellin, Colombia

Background: Polyarteritis nodosa (PAN) is the third most frequent vasculitis in pediatrics, Cutaneous PAN (CPAN) being more common that Systemic PAN (SPAN). CPAN is frequently described as a benign disease. In children, PAN onset is frequent between 9 and 11 years of age, with no sex differences, and its clinical features may be nonspecific.

Objectives: To characterize pediatric patients who were diagnosed with CPAN and SPAN and to compare their clinical features, treatments, and outcome.

Methods: A descriptive study was conducted in two centers from Medellin- Colombia, using retrospective data from January 2010 to December 2019. Patients under 18 years of age classified as PAN according to EULAR/PRINTO/ PRES(1) criteria were included. CPAN patients were defined according to EULAR/PRES definition (2). Data from medical records were registered, and were expressed in median and ranges and mean and standard deviation (SD) according to their distribution. A univariate analysis was carried out by comparing signs, symptoms, and treatment between CPAN and SPAN, and a $p$-value $<0,05$ was considered as significant.

Results: Twenty patients were included. The median age at diagnosis was ten years. $60 \%$ were boys. The median follow-up period was 27 months. CPAN was diagnosed in 11 (55\%) and SPAN in 9 patients (45\%). The most frequent symptoms were cutaneous manifestations (95\%), fever $(60 \%)$ and Calf Pain $(55 \%)$. Mucosal ulcers were described in four patients; 3 of them were defined as CPAN. Lingual necrosis was present in two CPAN, and peripheral nervous system involvement was found in one SPAN and two CPAN patients in skin affected with lesions; even though, no significant statistical differences between CPAN and SPAN were found in constitutional, cutaneous, muscle-skeletal symptoms, and acute phase reactants. Arteriographic anomalies as hepatic and renal microaneurysms, carotidal aneurysms without aortic involvement, and renal infarction were found in one patient each. Skin Biopsy was performed in 18 patients, being compatible with PAN in 16. All PAN patients (CPAN and SPAN) required treatment with glucocorticoids. None of the patients died during the follow-up period.

Conclusion: In this Colombian pediatric cohort of PAN patients, the disease was more common in boys than girls, and CPAN was more frequent than SPAN, as already been described. As is evident in this cohort, although CPAN has been considered a benign disease, these patients may be severely ill, requiring glucocorticoid treatment. Pediatric CPAN patients should be strictly followed with particular attention to identify systemic involvement, considering that constitutional, cutaneous, and muscle-skeletal features may be very similar between CPAN and SPAN.

References:

[1] Ozen S, Pistorio A, lusan S, et al. EULAR/PRINTO/PRES criteria for Henoch-Schönlein purpura, childhood polyarteritis nodosa, childhood Wegener granulomatosis and childhood Takayasu arteritis: Ankara 2008. Part II: Final classification criteria. Ann Rheum Dis. 2010 May;69(5):798-806.

[2] Ozen S, Ruperto N, Dillon M, et al. EULAR/PReS endorsed consensus criteria for the classification of childhood vasculitides. Ann Rheum Dis. 2006;65(7):936-41.

Disclosure of Interests: None declared

DOI: 10.1136/annrheumdis-2020-eular.6512

\section{FRI0469 ACTIVE INFECTION IN PEDIATRIC SYSTEMIC LUPUS ERYTHEMATOSUS (SLE)}

K. L. Luo ${ }^{1}$, J. H. Lee ${ }^{2}$, B. L. Chiang ${ }^{2}{ }^{1}$ National Taiwan University Children's Hospital, Taipei, Taiwan, Republic of China; ${ }^{2}$ National Taiwan University Children's Hospital, Taipei, Taiwan, Republic of China

Background: SLE is the autoimmune disease involving multiple systems Infections might mimic SLE flare, leading to confusion over the diagnosis and appropriate treatment. To distinguishing acute infection from active flare always remains a clinical challenge.

Objectives: We aim to explore the potential parameters in identifying active infection and disease activity in pediatric SLE. 